ISSN 2466-2232

Online ISSN 2466-2100

\title{
Correlation of Flux Ingredients with HAZ Width in Submerged Arc Welding
}

\author{
Brijpal Singh*, $\dagger$ \\ *Associate Professor, Mechanical Engineering Department, Maharaja Surajmal Institute of Technology, \\ New Delhi, 110058, India
}

†Corresponding author : brijpalsingh101@gmail.com

(Received July 20, 2017 ; Revised November 13, 2017 ; Accepted January 3, 2018)

\begin{abstract}
Fluxes play an important role in deciding weld metal properties. The properties of the welds in HAZ area are severely affected. In this study attempt has been made to evaluate the effect of flux composition on the width of the HAZ. The study reveals that FeMn and NiO both are having significant effect on HAZ width. The combined effect of $\mathrm{CaF}_{2}$, $\mathrm{FeMn}$ and $\mathrm{CaF}_{2}, \mathrm{NiO}$ is also significant. This study may help in selection of flux for minimum $\mathrm{HAZ}$ width in weldments.
\end{abstract}

Key Words : SAW, BI, HAZ, Flux

\section{Introduction}

In submerged arc welding, arc is produced between a electrode and the workpiece. Since the arc is submerged under a heavy coating of granular flux, hence it is called submerged arc welding. The welding process may be manual or automatic. This welding process gives high quality joint as double protection is obtained from atmospheric gases ${ }^{1}$. SAW is an automatic process. This welding process is used for carbon steels as well as nickel based alloys, stainless steels and other non-ferrous metals. Fluxes are the chemical substances that are used as a cleaning agent in welding. The SAW fluxes contain lime, silica, manganese oxide, calcium fluoride and other compounds. In SAW the weld pool is protected from the atmospheric contamination by being submerged under a blanket of granular fusible flux. In the molten state, the flux becomes conductive and provides a current path between the electrode and work piece. Fluxes can be categorized depending upon the method of manufacture, the extent to which they can affect the alloy content of the weld deposit and the effect on weld deposit properties ${ }^{2}$.

Agglomerated fluxes: These are also known as bonded fluxes. In agglomerated fluxes, the raw materials are powdered, dry mixed and bonded with either potassium silicate or sodium silicate. After bonding, the wet mixture is pelletized and baked at a temperature lower than that for fused fluxes. After this, the pellets are broken up, screened to size and packaging is done. These fluxes have lower bulk density and hence less flux is melted for a given amount of weld deposition. The main advantage of using agglomerated flux is that deoxidizers and other alloying elements can be added during the dry mixing but its main limitation is the absorption of moisture by the flux ${ }^{3)}$.

\section{Heat Affected Zone}

Heat affected Zone may be defined as the area of base metal which is not melted but its properties are affected by the heat of welding. The properties of the HAZ are changed due to change in the microstructure. The microstructure is changed due to heating and subsequent cooling. The extent and magnitude of property change depends on the base metal, welding process, flux composition and heat input by the welding process ${ }^{4)}$. The change in HAZ takes place in two stages. In first stage, the microstructural changes like grain growth takes place and in the second stage precipitation hardening and embrittlement of the metal takes place ${ }^{5)}$.

The literature review shows that many researchers have studied the effect of welding process parameters 
on HAZ microstructure and dimensions ${ }^{6,7)}$. The main aim of the studies was to have a minimum HAZ area by selecting optimum welding parameters. By selecting the flux for minimum HAZ from such studies, mechanical properties of the weldments can be improved. (Adler et. al., 1975), (Fisher, 1952).Lee et al. $(2000)^{8-10)}$ discussed the effect of welding parameters on the size of the HAZ and concluded that in HAZ, the grains are of large size .So, the toughness is reduced in HAZ area. While in a narrow HAZ, the temperature gradients are high but due to finer grain size, the toughness is improved.

Gunaraj and Murugan (2002) ${ }^{7)}$ studied the effect of welding process parameters and heat input on HAZ area and other metallurgical characteristics. The study concludes thatfor reducing HAZ proper selection of welding process parameters is required. The study reveals that HAZ is increased with increasing heat input and wire feed rate while it is reduced with increasing welding speed. Mathematical models were developed to study the effect of process variables and heat input on HAZ width, grain refinement and other metallurgical aspects

Heat affected zone affects the mechanical properties of the weld material as the HAZ microstructure has a strong influence on the weld joint properties. The ultimate tensile strength, $\mathrm{h}$ toughness and hydrogen cracking are the main problems which are associated with HAZ. The flux composition also has a definite effect on HAZ width, depth, area of penetration, area of reinforcement and weld dilution in mild steels, so the study and control of HAZ is very much essential. HAZ also increases the probability of fatigue failure at the weakest zone caused by heating and cooling of the weld zone.

\section{Experimental Procedure}

The fluxes were prepared by agglomeration technique. The base constituents $\mathrm{CaO}, \mathrm{SiO}_{2}$, and $\mathrm{Al}_{2} \mathrm{O}_{3}$ were mixed in the ratio 7:10:2 based on ternary and binary phase diagrams. The additives $\mathrm{CaF}_{2}, \mathrm{FeMn}$ and $\mathrm{NiO}$ were selected as control parameters. These additives were added to the base constituents and their effects on elements transferred to the welds were investigated. To investigate the effects systematically, twenty fluxes were designed using response surface methodology. The concentrations of the additives were varied in the range
$2-8 \%$. The control parameters (additives) and their levels are shown in the coded form in the table 1 . The three levels of the aforesaid additives are shown in table 2.The composition of wire and base plate are given in Table 3. The welding parameters were made constant for all the welds. These parameters are given in Table 4. All the components, base constituents and additives were mixed in a container and Potassium silicate was used as a binder for making these fluxes. After preparation the fluxes were heated in a furnace up to $400^{\circ} \mathrm{C}$ for more than six hours to remove any traces of moisture. Before making weld the fluxes were again heated up to

Table 1 Design matrix in coded form

\begin{tabular}{|c|c|c|c|}
\hline $\begin{array}{c}\text { No of } \\
\text { Experiment }\end{array}$ & $\mathrm{CaF}_{2} \mathrm{wt} \%$ & FeMn $w t \%$ & $\mathrm{NiO} w \mathrm{t} \%$ \\
\hline 1 & +1 & -1 & -1 \\
\hline 2 & 0 & +1 & 0 \\
\hline 3 & +1 & -1 & +1 \\
\hline 4 & -1 & -1 & -1 \\
\hline 5 & 0 & 0 & 0 \\
\hline 6 & 0 & 0 & 0 \\
\hline 7 & +1 & +1 & +1 \\
\hline 8 & 0 & 0 & 0 \\
\hline 9 & 0 & -1 & 0 \\
\hline 10 & +1 & 0 & 0 \\
\hline 11 & 0 & 0 & +1 \\
\hline 12 & -1 & -1 & +1 \\
\hline 13 & 0 & 0 & 0 \\
\hline 14 & 0 & 0 & 0 \\
\hline 15 & +1 & +1 & -1 \\
\hline 16 & -1 & 0 & 0 \\
\hline 17 & 0 & 0 & 0 \\
\hline 18 & 0 & 0 & -1 \\
\hline 19 & -1 & +1 & +1 \\
\hline 20 & -1 & +1 & -1 \\
\hline
\end{tabular}

Table 2 Showing three factors and their levels

\begin{tabular}{|c|c|c|c|c|}
\hline Factors & $\begin{array}{c}\text { Additives } \\
\%\end{array}$ & $\begin{array}{c}\text { Lower } \\
\text { level }(-1)\end{array}$ & $\begin{array}{c}\text { Middle } \\
\text { level }(0)\end{array}$ & $\begin{array}{c}\text { High } \\
\text { 1evel (+1) }\end{array}$ \\
\hline $\mathrm{A}$ & $\mathrm{CaF}_{2}$ & 2 & 5 & 8 \\
\hline $\mathrm{B}$ & $\mathrm{FeMn}$ & 2 & 5 & 8 \\
\hline $\mathrm{C}$ & $\mathrm{NiO}$ & 2 & 5 & 8 \\
\hline
\end{tabular}

Table 3 Showing wire and plate composition

\begin{tabular}{|c|c|c|c|c|c|c|}
\hline Composition & Carbon \% & Silicon \% & Manganese \% & Sulphur \% & Phosphorus \% & Nickel \% \\
\hline Base Plate & 0.03 & 0.07 & 0.34 & 0.017 & 0.022 & - \\
\hline Wire & 0.11 & 0.09 & 0.45 & 0.021 & 0.021 & - \\
\hline
\end{tabular}

The electrode wire used having diameter $3.15 \mathrm{~mm}$ and its specification was AWS- A5.17 El-8 
Table 4 Welding Parameters

\begin{tabular}{|c|c|c|c|}
\hline S.No. & Voltage & Current & Travel speed \\
\hline 1 & 30 volts & 475 ampere & $20 \mathrm{~cm} /$ minute. \\
\hline
\end{tabular}

Table 5 The measured parameters

\begin{tabular}{|c|c|c|c|c|c|c|c|}
\hline $\begin{array}{c}\text { Flux } \\
\mathrm{NO}\end{array}$ & $\begin{array}{c}\mathrm{CAF}_{2} \\
(\%)\end{array}$ & $\begin{array}{c}\mathrm{FeMn} \\
(\%)\end{array}$ & $\begin{array}{c}\text { NIO } \\
(\%)\end{array}$ & $\begin{array}{c}\mathrm{HAZ} \text { width } \\
(\mathrm{mm})\end{array}$ & $\mathrm{Mn}$ & $\Delta \mathrm{Mn}$ & $\mathrm{Ni}$ \\
\hline 1 & 8 & 2 & 2 & 3.45 & 0.17 & -0.267 & 0.177 \\
\hline 2 & 5 & 8 & 5 & 3.16 & 0.37 & -0.069 & 0.702 \\
\hline 3 & 8 & 2 & 8 & 4.38 & 0.23 & -0.209 & 0.544 \\
\hline 4 & 2 & 2 & 2 & 2.63 & 0.17 & -0.269 & 0.374 \\
\hline 5 & 5 & 5 & 5 & 2.19 & 0.35 & -0.089 & 0.388 \\
\hline 6 & 5 & 5 & 5 & 1.91 & 0.31 & -0.129 & 0.25 \\
\hline 7 & 8 & 8 & 8 & 2.35 & 0.38 & -0.059 & 0.477 \\
\hline 8 & 5 & 5 & 5 & 1.77 & 0.34 & -0.099 & 0.27 \\
\hline 9 & 5 & 2 & 5 & 2.17 & 0.34 & -0.099 & 0.474 \\
\hline 10 & 8 & 5 & 5 & 3.56 & 0.42 & -0.019 & 0.744 \\
\hline 11 & 5 & 5 & 8 & 1.28 & 0.15 & -0.289 & 1.33 \\
\hline 12 & 2 & 2 & 8 & 3.80 & 0.57 & 0.131 & 0.44 \\
\hline 13 & 5 & 5 & 5 & 1.75 & 0.38 & -0.059 & 0.32 \\
\hline 14 & 5 & 5 & 5 & 2.23 & 0.39 & -0.049 & 0.32 \\
\hline 15 & 8 & 8 & 2 & 5.10 & 0.24 & -0.199 & 0.054 \\
\hline 16 & 2 & 5 & 5 & 3.68 & 0.25 & -0.189 & 0.344 \\
\hline 17 & 5 & 5 & 5 & 2.25 & 0.50 & 0.061 & 0.452 \\
\hline 18 & 5 & 5 & 2 & 2.02 & 0.29 & -0.149 & 0.366 \\
\hline 19 & 2 & 8 & 8 & 2.64 & 0.33 & -0.109 & 0.502 \\
\hline 20 & 2 & 8 & 2 & 6.036 & 0.33 & -0.109 & 0.288 \\
\hline
\end{tabular}

$100^{\circ} \mathrm{C} . \mathrm{CaCO}_{3}$ was used in place of $\mathrm{CaO}$ because of its hygroscopic nature. The transfer of manganese was calculated by a $\triangle$ Delta quantity $=$ Analyzed composition - Expected composition. The Table 5 shows that $\triangle M n$ is negative for most of the welds and it can be taken as an indicator of weld oxygen content. The expected composition was calculated from the below given relation as given in equation 1 :

\section{Expected composition}

$$
\begin{aligned}
& =\frac{\text { dilution }^{*} \text { base plate composition }}{100} \\
& +\frac{(100-\text { dilution }) * \text { wire composition }}{100}
\end{aligned}
$$

Bead on plate welds using submerged arc welding were made on $18 \mathrm{~mm}$ thick plates. The composition of base plate and wire is given in table 3 . Welding parameters

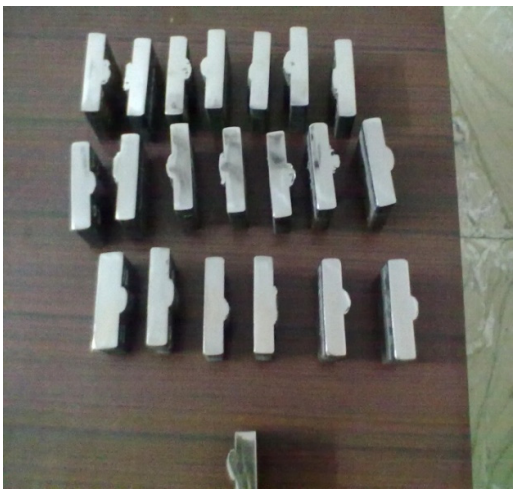

(a)

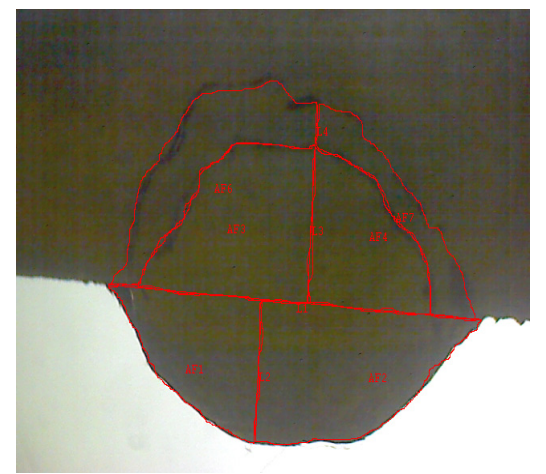

(b)

Fig. 1 (a) Photographs of bead on plate welds, (b) Showing width of HAZ

such as voltage, current and travel speed were made constant table 4 . Four beads were laid one over the other in order to minimize the effect of dilution. In this study $10 \%$ dilution from the base plate has been considered. After making beads, the powder was extracted from the top bead with the help of a drill machine for chemical analysis. The measure responses are given in Table 5 and the polished samples of bead and HAZ width are shown in Fig. 1(a) and (b).

\section{Result and Discussion}

As the flux composition has a definite effect on penetration, element transfer, bead geometry, physical properties of flux and chemical characteristics affect the HAZ in the weld. So an attempt has been made to study the effect of flux composition on width of the HAZ. The predictive equations of HAZ width have been developed in terms of flux composition. The experimental results for HAZ width are given in Table 5 and ANOVA results for HAZ width are given in Table 6.

\section{Development of model for width of HAZ}

The second order quadratic model developed for width of the HAZ, using surface methodology based on ex- 
Table 6 ANOVA Table for width of heat affected zone

\begin{tabular}{|c|c|c|c|c|c|c|c|}
\hline \multicolumn{8}{|c|}{ ANOVA for Response Surface Reduced Quadratic Model } \\
\hline \multicolumn{8}{|c|}{ Analysis of variance table [Partial sum of squares - Type III] } \\
\hline & Sum of & & \multicolumn{2}{|c|}{ Mean } & $\mathrm{F}$ & p-value & \\
\hline Source & Squares & $\mathrm{df}$ & \multicolumn{2}{|c|}{ Square } & Value & Prob. $>\mathrm{F}$ & \\
\hline Model & 27.88987 & 8 & \multicolumn{2}{|r|}{3.486} & 70.05 & $<0.0001$ & significant \\
\hline $\mathrm{A}-\mathrm{CaF}_{2}$ & 0.00025 & 1 & \multicolumn{2}{|r|}{0.000} & 0.01 & 0.9448 & \\
\hline B-FeMn & 0.81796 & 1 & \multicolumn{2}{|r|}{0.818} & 16.44 & 0.0019 & significant \\
\hline $\mathrm{C}-\mathrm{NiO}$ & 2.29441 & 1 & \multicolumn{2}{|r|}{2.294} & 46.10 & $<0.0001$ & significant \\
\hline $\mathrm{AB}$ & 0.864613 & 1 & \multicolumn{2}{|r|}{0.865} & 17.37 & 0.0016 & significant \\
\hline $\mathrm{BC}$ & 8.507813 & 1 & \multicolumn{2}{|r|}{8.508} & 170.95 & $<0.0001$ & significant \\
\hline $\mathrm{A}^{\wedge} 2$ & 6.743196 & 1 & \multicolumn{2}{|r|}{6.743} & 135.49 & $<0.0001$ & significant \\
\hline $\mathrm{B}^{\wedge} 2$ & 1.026327 & 1 & \multicolumn{2}{|r|}{1.026} & 20.62 & 0.0008 & significant \\
\hline $\mathrm{C}^{\wedge} 2$ & 0.449046 & 1 & \multicolumn{2}{|r|}{0.449} & 9.02 & 0.0120 & significant \\
\hline Residual & 0.547448 & 11 & \multicolumn{2}{|r|}{0.050} & & & \\
\hline Lack of Fit & 0.274114 & 6 & \multicolumn{2}{|r|}{0.046} & 0.84 & 0.5899 & not significant \\
\hline Pure Error & 0.273333 & 5 & \multicolumn{2}{|r|}{0.055} & & & \\
\hline Cor Total & 28.43732 & 19 & & & & & \\
\hline & \multicolumn{2}{|c|}{ Std. Dev. } & 0.224 & \multicolumn{2}{|c|}{ R-Squared } & 0.98107 & \\
\hline & \multicolumn{2}{|c|}{ Mean } & 2.92 & \multicolumn{2}{|c|}{ Adj R-Squared } & 0.9667 & \\
\hline & & & 7.65 & & R-Squared & 0.9203 & \\
\hline & & & 2.19 & & Precision & 31.91 & \\
\hline
\end{tabular}

perimental results is given in the equation. The predicted equation is given in terms of actual factors is given in equation 2 .

$$
\begin{aligned}
\text { HAZ Width } & =3.491-1.530 * \mathrm{CaF}_{2}+0.172 * \mathrm{FeMn} \\
& +0.862 * \mathrm{NiO}-0.0360 * \mathrm{CaF}_{2} * \mathrm{FeMn} \\
& -0.145 * \mathrm{FeMn} * \mathrm{NiO}+0.1739 \mathrm{CaF}_{2}^{2} \\
& +0.0678 * \mathrm{FeMn}^{2}-0.0448 * \mathrm{NiO}^{2}
\end{aligned}
$$

\section{ANOVA Results for width of HAZ}

The ANOVA results for HAZ width are given in Table 6. The model F- Value of 70.05 implies that the model is significant. There is only a $0.01 \%$ chance that a "model F- value" this large could occur due to noise. It can be seen from the Table 6 that the factors $\mathrm{B}$ and $\mathrm{C}$, Interactions of $\mathrm{BC}$ and $\mathrm{AC}$ and quadratic terms $\mathrm{A}^{2}, \mathrm{~B}^{2}$ and $C^{2}$ all are having significant effect on HAZ width.

The multi regression coefficient of the model is 0.9812. This means $98.12 \%$ of the variance in HAZ width can be explained by the independent variables. The Figs. 2 and 3 depict the normal plot of residuals and predicted vs actual value plot for the response. It is observed from Fig. 2 that the residuals fall on a straight

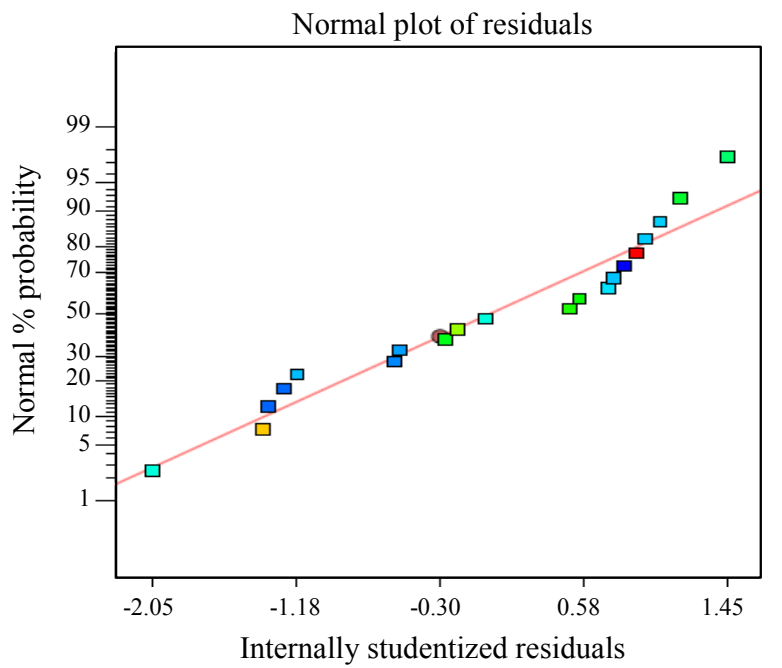

Fig. 2 Normal plot of residuals for HAZ width

line and the Fig. 3 illustrates that the difference between the predicted and actual value of the response is insignificant. The lack of fit is insignificant relative to the pure error. The "pred. R-Squared" of 0.9203 and "Adj. R-squared" of 0.9667 are in close agreement. This implies that the proposed model is adequate and it can be 


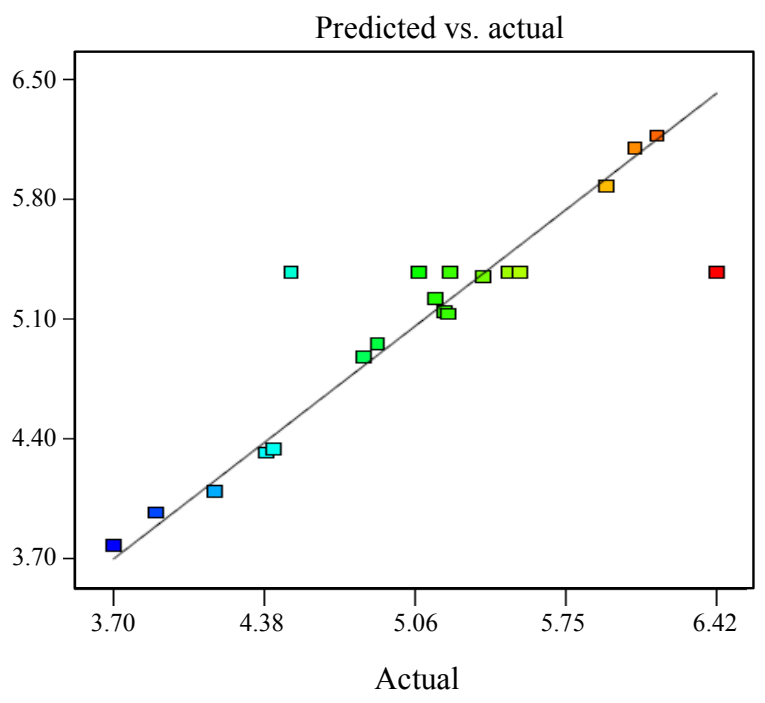

Fig. 3 Predicted vs actual values for HAZ width

used to determine the effect of various parameters on the responses.

\section{Effect of FeMn additive on width of HAZ}

The effect of FeMn content on the width of HAZ is depicted in the Fig. 4. This shows that after an initial decrease, the width of HAZ increases. It can be attributed to the change of oxygen content in the weld, which consequently affects the surface tension of the liquid flux and the bead geometry. A small amount weld oxygen act as a surface active agent which changes the direction of surface tension gradient from negative to positive, thus reversing Marangoni convection and the flow of liquid takes place in downward making deeper penetration $^{11)}$. So the heat may be confined to a small area. If the oxygen may be large the liquid flow will take place in the out ward direction causing to spread the heat over a large area. Weld Mn content does not show any significant effect on width of heat affected zone as shown

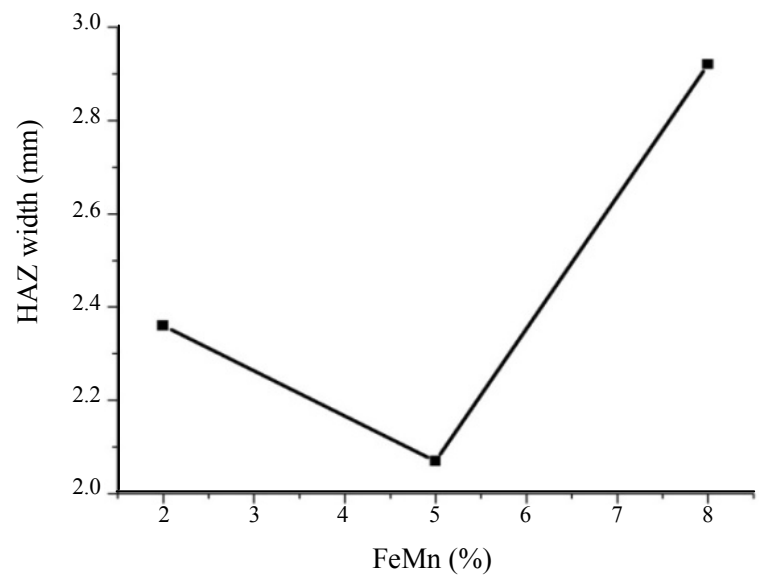

Fig. 4 Effect of FeMn on HAZ width

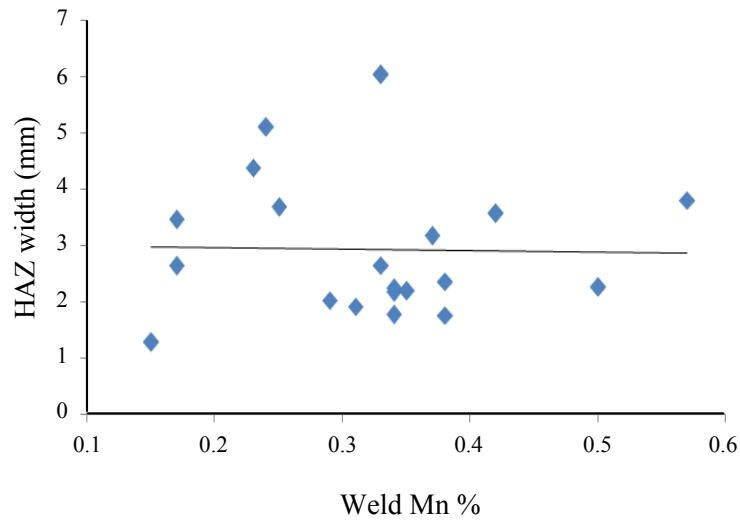

Fig. 5 Variation of HAZ width with weld Mn

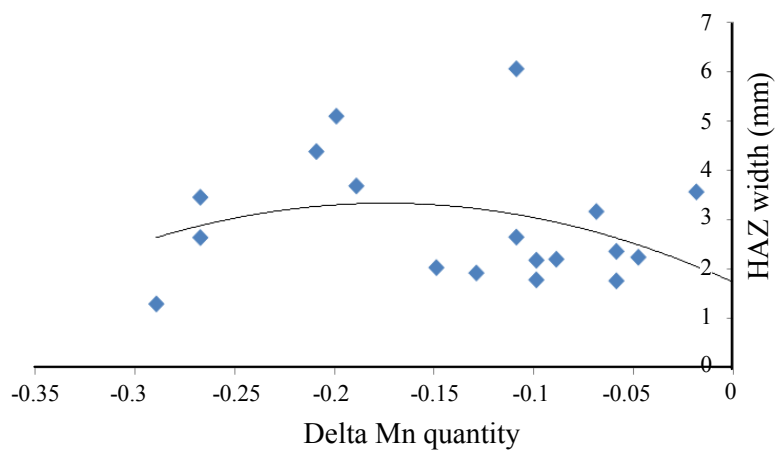

Fig. 6 Variation of HAZ with weld Oxygen

in Fig. 5. The variation of HAZ width with the weld oxygen content has been given in Fig. 6. This shows that HAZ width is small when the oxygen content is either very low or very high.

\section{Effect of $\mathrm{NiO}$ additive on HAZ width}

The effect of $\mathrm{NiO}$ additive on $\mathrm{HAZ}$ width is given in the Fig. 7. It can be observed from the Fig. 7 that the $\mathrm{HAZ}$ width decreases with increase in $\mathrm{NiO}$ additive in the flux. Two possible reasons may exist for it, one may be the weld oxygen content and the other may be the increased penetration with increasing $\mathrm{NiO}$. The HAZ

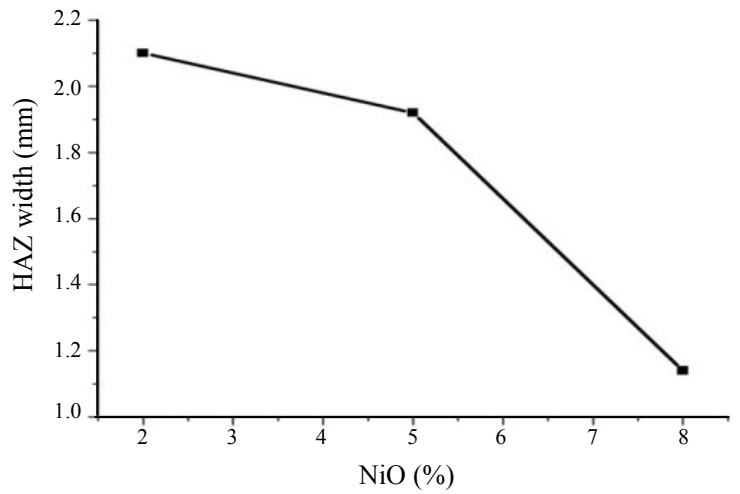

Fig. 7 Effect of $\mathrm{NiO}$ on $\mathrm{HAZ}$ width 


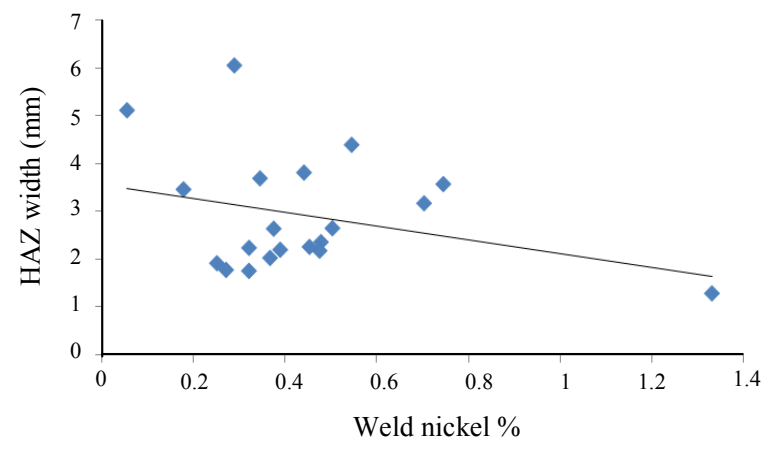

Fig. 8 Correlation of Ni with HAZ width

Table 7 Predicted and Experimental values

\begin{tabular}{|c|c|c|c|c|c|c|}
\hline S.No. & $\mathrm{CaF}_{2} \%$ & $\begin{array}{c}\mathrm{FeMn} \\
\%\end{array}$ & $\begin{array}{c}\mathrm{NiO} \\
\%\end{array}$ & $\begin{array}{c}\text { Weld } \\
\mathrm{HAZ} \\
\text { width } \\
\text { predicted }\end{array}$ & $\begin{array}{c}\text { Experimental } \\
\text { value of } \\
\text { HAZ width }\end{array}$ & $\begin{array}{c}\text { Error } \\
\%\end{array}$ \\
\hline 1 & 2 & 2 & 5 & 3.34 & 3.50 & 4.7 \\
\hline 2 & 5 & 2 & 8 & 6.74 & 6.3 & 6.5 \\
\hline
\end{tabular}

width may depend upon the quantity of Nickel and oxygen transferred to the weld. $\mathrm{NiO}$ is not very stable oxide and at high temperature it decomposes into $\mathrm{Ni}$ and oxygen. Nickel transfer reduces the HAZ width as shown in the Fig. 8. The HAZ width initially increases with increasing weld oxygen content but it is reduced slightly with further increase of oxygen content as shown in Fig. 6. With addition of $\mathrm{NiO}$ both oxygen and $\mathrm{Ni}$ contents increases and the basicity index also increases simultaneously. The correlation of Ni proportion transfer with the width of the HAZ shows a decrease in the HAZ width with increasing Nickel proportion transfer to the weld.

\section{Validation of the model}

The validation of the model was done by selecting two fluxes within the given range .The results are tabulated in Table 7 given below and the error lies within the permissible limit. It shows that the model can be used for predicting the values of HAZ width for the given flux composition.

\section{Conclusions}

1) $\mathrm{FeMn}$ and $\mathrm{NiO}$ both additives as individuals are having synergistic effect on HAZ width but as a mixture, these are having anti synergistic effect on HAZ width.
2) After decreasing to a minimum, the HAZ width increases with increasing FeMn additive.

3) The HAZ width is reduced with increasing $\mathrm{NiO}$ content in the flux but weld $\mathrm{Mn}$ content does not show any effect of HAZ width. However, it is reduced with increasing $\mathrm{Ni}$ addition.

4) The width of the HAZ has a reducing trend with increasing Ni content.

5) Quadratic modelling can be used to predict the effect of flux on HAZ width.

ORCID: Brijpal Singh: http://orcid.org/0000-0002-5418-033X

\section{References}

1. Hould Croft PT., Submerged arc welding, Second Ed. London, Abington publishing, Cambridge, (1998)

2. Kumar V., Devolopment and characterization of fluxes for submerged arc welding, Ph.D Theis, Punjabi University Punjab, India, (2011)

3. Maheshwari S., Study of Element Transfer behaviour during submerged arc welding, Ph.D. Thesis, Indian Institute of Technology Delhi, India, (1998)

4. Weman Klas, Welding process hand book, First Ed. New York, CRC press Boston, (2003)

5. Lancaster JF, The metallurgy of welding Brazing and Soldering, $6^{\text {th }}$ Ed.London, George Allen Unvin, (1999)

6. Linert G E. Welding Metallurgy, Fundamentals, $4^{\text {th }}$ Ed. New York, American Welding Society, (1995)

7. Gunaraj V and Murugan N., Rediction of heat affected zone characteristics in submerged arc welding of structural steel pipes. Welding Research, 81(2002), 94-98

8. Adler YP, Markov EV and Granovsky YV., The design of experiment to find optimal condition. USSR, MIR Publisher, Moscow, (1975)

9. Fisher RA., Statistical methods for research workers, $12^{\text {th }}$ Edition, Scotland, Oliver and Boyd Dinburg, (1952)

10. Lee CS, Chandel RS and Seow HP., Effect of welding parameters on the size of heat affected zone of submerged arc welding, Materials and manufacturing process, 15(5) (2000), 649-666 https://doi.org/10.1080/10426910008913011

11. Gunaraj V and Murugan N., Rediction of heat affected zone characteristics in submerged arc welding of structural steel pipes. Welding Research, 81(2002), 94-98

12. Heiple CR and Roper JR., Mechanism for minor element effect on GTA fusion zone geometry 1982, Welding research supplement, 97-102 